\title{
Inheritance of Resistance to Colletotrichum gloeosporioides and $C$. acutatum in Strawberry
}

\author{
Raymond L. Jacobs, ${ }^{1}$ Tika B. Adhikari, ${ }^{2, \dagger}$ Jeremy Pattison, ${ }^{1}$ G. Craig Yencho, ${ }^{1}$ Gina E. Fernandez, ${ }^{1}$ and Frank J. Louws ${ }^{1,2, \dagger}$ \\ ${ }^{1}$ Department of Horticultural Science; and ${ }^{2}$ Department of Entomology and Plant Pathology, North Carolina State University, Raleigh 27695 \\ Accepted for publication 21 September 2018.
}

\begin{abstract}
Information on the inheritance of resistance to Colletotrichum gloeosporioides and C. acutatum hemibiotrophic infections (HBI) in strawberry leaf tissue and the genetic control of anthracnose crown rot (ACR) in crown tissue are relatively unknown. Six parental genotypes were crossed in a half-diallel mating design to generate 15 full-sib families. HBI and ACR experiments were conducted concurrently. Both seedlings and parental clones were inoculated with $1 \times 10^{6}$ conidia $/ \mathrm{ml}$ of C. gloeosporioides or C. acutatum. Percent sporulating leaf area, wilt symptoms, and relative area under the disease progress curve were calculated to characterize resistance among genotypes and full-sib families. Low dominance/additive variance ratios for $C$. acutatum HBI (0.13) and C. gloeosporioides ACR (0.20) were observed, indicating

additive genetic control of resistance to these traits. Heritability estimates were low for $C$. acutatum HBI $(0.25)$ and $C$. gloeosporioides HBI $(0.16)$ but moderate for $C$. gloeosporioides ACR (0.61). A high genetic correlation $\left(\mathrm{r}_{\mathrm{A}}=0.98\right)$ between resistance to $C$. acutatum $\mathrm{HBI}$ and C. gloeosporioides HBI was observed, suggesting that resistance to these two Colletotrichum spp. may be controlled by common genes in strawberry leaf tissue. In contrast, negative genetic correlations between ACR and both HBI traits $\left(\mathrm{r}_{\mathrm{A}}=-0.85\right.$ and -0.61$)$ suggest that resistance in crown tissue is inherited independently of resistance in leaf tissue in the populations tested. Overall, these findings provide valuable insight into the genetic basis of resistance, and the evaluation and deployment of resistance to HBIs and ACR in strawberry breeding programs.
\end{abstract}

Anthracnose crown rot (ACR) and anthracnose fruit rot (AFR), caused by Colletotrichum gloeosporioides (Penz.) Penz. \& Sacc. sensu lato (teleomorph: Glomerella cingulata (Stoneman) Spauld. $\&$ H. Schrenk), and C. acutatum sensu lato J. H. Simmonds, respectively, are the most challenging diseases of cultivated strawberry (Fragaria $\times$ ananassa Duchesne) in North Carolina (Poling 2008). Traditionally, host specificity or preference and conidia morphology have been focal criteria for species delimitation in the genus Colletotrichum (Denoyes-Rothan et al. 2003; Legard 2000; Sutton 1992). However, host-fungus associations within Colletotrichum spp. are highly variable. Utilizing the multilocus phylogenetic analysis, isolates of C. gloeosporioides and $C$. acutatum have been considered as $C$. gloeosporioides species complex and $C$. acutatum species complex, respectively (Baroncelli et al. 2015; Damm et al. 2012; Weir et al. 2012). However, to be consistent with past literatures these pathogens of strawberry will be referred to here as $C$. gloeosporioides and C. acutatum.

In strawberry, ACR symptoms develop in plants by rapidly invading and producing a reddish-brown, marbled necrosis of crown tissue, resulting in wilt and eventual collapse of plants (Rahman et al. 2015). AFR produces dark, sunken lesions on developing fruit that render them unmarketable (Freeman and Katan 1997; Rahman et al. 2013). More importantly, asymptomatic

†Corresponding authors: T. B. Adhikari; E-mail: tbadhika@ncsu.edu; and F. J. Louws; frank_louws@ncsu.edu

Funding: This project was funded by the NC Strawberry Association, the North American Strawberry Grower Association, and the Southern Region Small Fruit Consortium.

Current address of R. L. Jacobs: Driscoll's, Inc., 12880 E. US Highway 92, Dover, FL 33527.

Current address of J. Pattison: Driscoll's, Inc., 151 Silliman Road, Watsonville, CA 95076 .

The author(s) declare no conflict of interest.

(c) 2019 The American Phytopathological Society nursery stock carrying quiescent Colletotrichum infections are the predominant source of inoculum in fruiting fields and have been implicated in many anthracnose epidemics in the southeastern United States (Delp and Milholland 1980; Leandro et al. 2003; MacKenzie et al. 2009; Poling 2008; Smith 2008). Once inoculum is introduced to a production field, it can continue to proliferate through secondary conidia to initiate new hemibiotrophic infections (HBI) or can survive epiphytically on leaf tissue (Leandro et al. 2001; Legard 2000). Overall incidence and severity of ACR and AFR are affected by several resistance mechanisms, including direct resistance of the crown and fruit tissue as well as rate-limiting mechanisms that inhibit proliferative components of the disease cycle such as colonization of foliage or proliferation through secondary infection (Gan et al. 2013; Rahman et al. 2013). Although previous studies have identified genetic variation in resistance to ACR and AFR based on crown and fruit tissues (Anciro et al. 2018; Ballington et al. 2002; DenoyesRothan et al. 2005; Gupton and Smith 1991; MacKenzie et al. 2006; Osorio et al. 2014; Smith and Spiers 1982), few studies have characterized resistance to Colletotrichum HBI in strawberry foliage, a common and critical host tissue in the disease cycles of both C. gloeosporioides and C. acutatum (Gan et al. 2013; Rahman et al. 2013).

Denoyes-Rothan et al. (2005) inoculated 64 seedling families with C. acutatum to identify a single dominant resistance gene (Rca2). Although seedlings were inoculated by spraying leaves to runoff, disease ratings were based on visible necrosis of leaves, petioles, and crown tissues and are more representative $C$. acutatum's rapid necrotrophic phase of infection rather than prolonged and symptomless HBI. Rahman et al. (2013) evaluated 14 strawberry genotypes for resistance to AFR and foliar HBI of $C$. acutatum in North Carolina. Although they found significant variation in resistance to AFR and HBI among genotypes, these traits were moderately correlated $(r=$ $0.57, P<0.005)$ within genotypes. Osorio et al. (2014) inoculated 42 full-sib families and clones with C. gloeosporioides in Florida and North Carolina and evaluated plant collapse over the course of a season. They reported that both narrow-sense heritability and broadsense heritability for clones and seedlings were higher in North 
Carolina than in Florida. Furthermore, the seedling tests showed higher genetic control than the clonal tests at both locations (Osorio et al. 2014). Anciro et al. (2018) screened individuals from 62 crosses of 24 parents for ACR and reported the first quantitative trait loci (QTL) for resistance to ACR caused by $C$. gloeosporioides. This QTL, named $\mathrm{FaRCg} 1$ and located on linkage group $6 \mathrm{~B}$, accounted for 26.8 to $29.8 \%$ of genetic variation for resistance in 2013 to 2014 and $17 \%$ in 2015 to 2016.

Foliar resistance is often described as rate-limiting (or ratereducing) resistance, a form of partial resistance wherein a host is susceptible to initial infection but possesses the capacity to reduce subsequent production of secondary conidia (Parlevliet 1979). Rate-limiting resistance is generally a durable and quantitatively inherited form of resistance that impedes epidemics through reductions in pathogen reproduction and development (Ballington et al. 2002; Ram 2014; Van der Plank 1968). Colletotrichum HBI in nurseries and the subsequent distribution of asymptomatic infected plant material is a major source of anthracnose epidemics in fruiting fields in North Carolina (F. J. Louws, unpublished data). Although previous studies were conducted to identify and compare resistance across strawberry genotypes (Anciro et al. 2018; Osorio et al. 2014; Rahman et al. 2013), there are no comparisons of the genetic components of resistance to ACR and HBI in crown and leaf tissue. We hypothesized that variation in resistance may exist in strawberry genotypes against Colletotrichum HBI which could be deployed as a form of rate-limiting resistance to curtail the spread of Colletotrichum spp. within strawberry nurseries and fruiting fields. Breeding for resistance to Colletotrichum HBI is one of the top priorities in the strawberry breeding program at North Carolina State University, Raleigh. The main objectives of this study were to determine the inheritance of rate-limiting resistance to $C$. gloeosporioides and $C$. acutatum $\mathrm{HBI}$ in strawberry leaf tissue and to compare this with the inheritance of resistance to ACR in strawberry crown tissue.

\section{MATERIALS AND METHODS}

Selection of genotypes and plant production. In total, 6 parental genotypes were selected from 18 genotypes previously screened for resistance to HBI and ACR (Table 1). Briefly, 18 strawberry genotypes were selected for further testing based on field observations of ACR and previous response to HBI. Apparent disease-free clonal plants of each genotype were grown to maturity in a greenhouse and leaves were inoculated with suspensions of $C$. gloeosporioides or C. acutatum conidia of $1.0 \times 10^{6}$ conidia/ml. Leaves were collected $7,14,21$, and 28 days after inoculation and percent sporulating leaf area (PSLA) was measured to gauge resistance to HBI. After foliar evaluations, plant crowns were inoculated with suspensions of C. gloeosporioides conidia of $1.0 \times 10^{6} \mathrm{conidia} / \mathrm{ml}$ and evaluated weekly using a six-point disease index. Disease ratings were used to calculate relative area under the disease progress curve (rAUDPC) scores, representing a proportion of maximum possible ACR severity. NCS 10-147, NCS 10-080, and $\mathrm{NCH}$ 11-304 averaged among the lowest PSLA and rAUDPC scores and were selected as parents for their apparent resistance to HBI and ACR. NCL 11-185 and cultivar Treasure had moderate rAUDPC scores but ranked among the most susceptible in their response to HBI. Cultivar Chandler was one of the most susceptible genotypes tested across all HBI and ACR phenotypes. These six parents were selected for inclusion in the current study for their range of resistance responses to HBI and ACR.

Development of strawberry populations. Six parents were crossed in a half-diallel mating design, Griffing's Method II, Model 1 (fixed), with a total of $[p(p-1)] / 2=15$ crosses made from $P=6$ parents. This mating design was selected for its ability to provide good estimates of general combining ability (GCA) and specific combining ability (SCA) under the characteristics of this study (i.e., a reduced number of nonrandom parents used without reciprocal crosses) (Griffing 1956). GCA is the average performance of a genotype across all hybrid combinations, while SCA is deviation of the performance of hybrid combinations from the expected based on parental GCA. Crosses were made at the Plants for Human Health Institute at the North Carolina Research Campus in Kannapolis, NC and seed were bulked to achieve sufficient seed numbers for 14 of the 15 crosses. NCS $10-080$ is male-sterile and was used as a female but only produced

TABLE 1. Means for resistance to hemibiotrophic foliar infections (HBI) of Colletotrichum acutatum (Ca HBI) and C. gloeosporioides (Cg HBI) and anthracnose crown rot (ACR) caused by $C$. gloeosporioides $(\mathrm{Cg} \mathrm{ACR}$ ) on 18 strawberry genotypes

\begin{tabular}{|c|c|c|c|c|}
\hline & & $\mathrm{Ca} \mathrm{HBI}$ & $\mathrm{Cg} \mathrm{HBI}$ & $C g$ ACR \\
\hline Strawberry genotype & Pedigree & Mean PSLA ${ }^{\mathrm{w}}$ & Mean PSLA ${ }^{\mathrm{w}}$ & Mean rAUDPC ${ }^{x}$ \\
\hline Treasure & A3 $\times$ Oso Grande & $32.8 * * *$ & $20.9 * * *$ & $0.53 \mathrm{~cd}$ \\
\hline Camino Real & Cal $89.230-7 \times$ Cal $90.253-3$ & 23.5 & 19.9 & $0.93 \mathrm{a}$ \\
\hline NCS 11-107 & Camino Real $\times$ Treasure & $23.0 * *$ & $15.7 * *$ & $0.47 \mathrm{de}$ \\
\hline Sweet Charlie & FL $80-456 \times$ Pajaro & 22.6 & 18.4 & $0.45 \mathrm{de}$ \\
\hline NCL 11-208 & Winter Dawn $\times$ Sabrosa & 22.0 & 17.1 & $0.68 \mathrm{bc}$ \\
\hline NCH 11-309 & Pelican $\times$ Camino Real & 21.9 & 19.0 & $0.26 \mathrm{fg}$ \\
\hline Chandler $^{\mathrm{y}}$ & Douglas $\times$ Cal 72.361-105 & 21.5 & 20.9 & $0.88 \mathrm{a}$ \\
\hline NCL 11-185y & NCC $99-27 \times$ Camino Real & 21.3 & 20.7 & $0.64 \mathrm{bc}$ \\
\hline Albion & Diamante $\times$ CA $94.16-1$ & 20.7 & 18.7 & $0.89 \mathrm{a}$ \\
\hline NCS $11-113$ & Camino Real $\times$ Sweet Charlie & 19.5 & 16.5 & $0.64 \mathrm{bc}$ \\
\hline Festival & Rosa Linda $\times$ Oso Grande & $18.9 *$ & $26.2 *$ & $0.71 \mathrm{~b}$ \\
\hline NCS $10-193$ & Chandler $\times$ Sweet Charlie & 18.1 & 16.2 & $0.72 \mathrm{~b}$ \\
\hline $\mathrm{NCH} 11-319$ & NCH 09-068 × Winter Dawn & 17.2 & 13.8 & $0.15 \mathrm{~g}$ \\
\hline Pelican & FL $82-1556 \mathrm{P} \times$ LA 8311 & 16.9 & 13.9 & $0.05 \mathrm{~h}$ \\
\hline $\mathrm{NCH} 11-304^{y}$ & NCH 09-068 × Winter Dawn & 14.4 & 13.2 & $0.13 \mathrm{gh}$ \\
\hline NCS $10-080^{y}$ & NCC $02-063 \times$ Open pollinated ${ }^{z}$ & 11.9 & 8.8 & 0.35 ef \\
\hline NCH 09-068 & NCC $99-42 \times$ NCC $87-45$ & 11.8 & 13.2 & $0.14 \mathrm{~g}$ \\
\hline NCS $10-147 y$ & Treasure $\times$ Chandler & 7.6 & 9.3 & $0.22 \mathrm{fg}$ \\
\hline
\end{tabular}

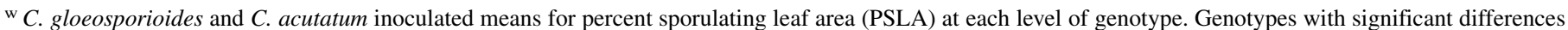
were compared between $C$. gloeosporioides and $C$. acutatum and are denoted by $*$ significant at $P \leq 0.05$, ** significant at $P \leq 0.005$, and $* * *$ significant at $P \leq$ 0.001 .

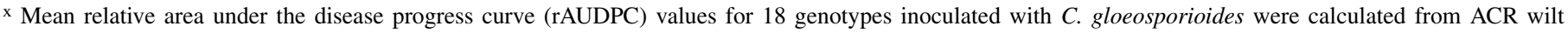
severities (as described in Materials and Methods). Genotypes with the same letter are not significantly different $(P \leq 0.05)$.

y Six genotypes were selected as parents for use in a half-diallel mating in the present study.

z NCS 10-080 was derived from the open-pollinated seed of NCC 02-063. 
enough seed to be included in the HBI experiment. In total, 1,024 strawberry genotypes from 15 full-sib families were developed to evaluate for resistance to Colletotrichum HBI in leaf tissue and 560 genotypes from 14 full-sib families were evaluated for resistance to ACR in crown tissue (Table 2). Approximately 400 seed were produced from each cross. All seed from each cross were scarified by immersion for $10 \mathrm{~min}$ in $18 \mathrm{M}$ sulfuric acid and then rinsed with double-distilled water. Scarified seed were stratified by placing them in 50-ml centrifuge tubes half-filled with slightly moistened vermiculite. Sealed tubes were placed in a $4^{\circ} \mathrm{C}$ refrigerator for 2 weeks. Scarified and stratified seed from each cross were sown onto separate 27.8-by-54.5-cm 1020 trays (T. O. Plastics, Inc., Clearwater, MN) partially filled with Fafard superfine germinating mix (Sun Gro Horticulture, Agawam, MA). Seed were covered with a light $(<2 \mathrm{~mm})$ layer of superfine germinating mix, misted with water, and covered with clear plastic humidity domes (T. O. Plastics, Inc.). Prepared trays were germinated in a clean growth room with no history of strawberry pathogens. Seedling trays were placed in a $21^{\circ} \mathrm{C}$ growth room under T5 light fixtures (EnviroGro; Hydrofarm Inc., Petaluma, CA) with 14-h day length. Once seedlings had two true leaves, they were transplanted to 50-cell plug trays containing Fafard 3B mix and maintained under periodic mist (30-s duration, 10-min interval) in a $21 \pm 5^{\circ} \mathrm{C}$ greenhouse for 3 to 4 days until new roots developed. In addition to the development of strawberry genotypes, clonal plants of each parental genotype were prepared. Apparent diseasefree runner tips of parental genotypes were collected from greenhouse-grown mother plants and rooted in 50-cell plug trays under periodic mist.

Seedlings and clonal plants were grown in a $21 \pm 5^{\circ} \mathrm{C}$ greenhouse away from other strawberries. Plants received supplemental lighting (15-h photoperiod, $500 \mathrm{ft}$ candles) throughout the experiment in addition to natural daylight to maintain active vegetative growth during short days. Plants were watered daily and, after 1 month, were fertilized daily with Jack's Professional LX Ca-Mg 15-5-15 fertilizer (JR Peters Inc., Allentown, PA) via a Dosatron injector system calibrated to dispense $100 \mathrm{ppm}$ N. Flowers and runners were removed weekly from seedlings to encourage new vegetative growth. In total, 120 individuals of each full-sib family and 60 clonal plants of each parental genotype were produced and included in these experiments. In all, individuals (40 assigned for inoculation by each species) from each family (Table 3) and 40 clonal plants (20 assigned for inoculation by each species) of each parental genotype were allocated to the HBI experiment, and 40 individuals from each family (Table 3) and 20 clonal plants of each genotype were allocated to the ACR experiment. Due to poor seed germination, only 61 individuals from the cross of NCS $10-080 \times \mathrm{NCH} 11-304$ were available for the HBI experiment.

Inoculum preparation and inoculation. Three representative isolates obtained from infected plant tissue in North Carolina which had previously proven pathogenic on Chandler strawberry through Koch's postulates (F. J. Louws, unpublished data) were used in this study. C. gloeosporioides and C. acutatum were revived from filter paper disks in long-term storage on half-strength Difco acidic potato dextrose agar (A-PDA). Revived cultures were transferred to fresh A-PDA plates and incubated at $25^{\circ} \mathrm{C}$ for 10 days under $12 \mathrm{~h}$ of fluorescent lighting. Inoculum of each isolate was prepared by flooding the plates with double-distilled water and filtered through a doubled layer of cheesecloth to remove mycelial debris. The inoculum concentration of each isolate was adjusted to $1.0 \times 10^{6} \mathrm{conidia} / \mathrm{ml}$ using a hemocytometer. Equal volumes of inoculum concentration of each isolate were mixed and used for inoculations For HBI experiments, plants were spray inoculated

TABLE 4. Analysis of variance for resistance to hemibiotrophic infections (HBI) of Colletotrichum acutatum and C. gloeosporioides in strawberry leaf tissue

\begin{tabular}{lrc}
\hline Source of variation & df & Mean square $^{\mathrm{z}}$ \\
\hline Block & 3 & 2.54 \\
Treatment (Colletotrichum sp.) & 1 & 0.15 \\
Block $\times$ treatment & 3 & 1.91 \\
Genotype & 20 & $14.85^{* * *}$ \\
Parent & 5 & $6.73^{*}$ \\
Cross & 14 & $6.00^{*}$ \\
Treatment $\times$ genotype & 20 & 2.36 \\
Treatment $\times$ parent & 5 & 1.91 \\
Treatment $\times$ cross & 14 & 1.57 \\
Block $\times$ genotype & 60 & 2.40 \\
Block $\times$ treatment $\times$ genotype & 60 & 2.15 \\
\hline
\end{tabular}

z Level of significance: $* * *$, and $* * *$ indicate $P<0.05,0.01$, and 0.001 , respectively.

TABLE 2. Summary of strawberry genotypes evaluated for resistance to Colletotrichum spp. in this study

\begin{tabular}{|c|c|c|c|c|}
\hline Experiment & Pathogen & Full-sib families & Genotypes & Observations \\
\hline \multirow[t]{2}{*}{ Hemibiotrophic infection (HBI) } & Colletotrichum acutatum & 15 & 548 & 548 \\
\hline & C. gloeosporioides & 15 & 476 & 547 \\
\hline Anthracnose crown rot & C. gloeosporioides & $14^{\mathrm{z}}$ & 560 & 4,480 \\
\hline
\end{tabular}

${ }^{z}$ Progeny of the cross NCS 10-080 $\times$ NCH 11-304 were included only in HBI experiments due to poor seed germination.

TABLE 3. Half-diallel mating design for six parents shared between two experiments ${ }^{\mathrm{x}}$

\begin{tabular}{|c|c|c|c|c|c|c|c|c|c|c|c|c|}
\hline \multirow[b]{2}{*}{ Parent } & \multicolumn{6}{|c|}{ HBI experiment ${ }^{y}$} & \multicolumn{6}{|c|}{ ACR experiment } \\
\hline & TR & $\mathrm{CH}$ & 147 & 185 & 304 & 080 & TR & $\mathrm{CH}$ & 147 & 185 & 304 & 080 \\
\hline TR & $\ldots$ & $\ldots$ & $\ldots$ & $\ldots$ & $\ldots$ & $\ldots$ & $\ldots$ & $\ldots$ & $\ldots$ & $\ldots$ & $\ldots$ & $\ldots$ \\
\hline $\mathrm{CH}$ & $33 / 32$ & $\ldots$ & $\ldots$ & $\ldots$ & $\ldots$ & $\ldots$ & 40 & $\ldots$ & $\ldots$ & $\ldots$ & $\ldots$ & $\ldots$ \\
\hline 147 & $39 / 34$ & $36 / 30$ & $\ldots$ & $\ldots$ & $\ldots$ & $\ldots$ & 40 & 40 & $\ldots$ & $\ldots$ & $\ldots$ & $\ldots$ \\
\hline 185 & $38 / 32$ & $35 / 25$ & $35 / 30$ & $\ldots$ & $\ldots$ & $\ldots$ & 40 & 40 & 40 & $\ldots$ & $\ldots$ & $\ldots$ \\
\hline 304 & $40 / 38$ & $37 / 33$ & $40 / 37$ & $35 / 31$ & $\ldots$ & $\ldots$ & 40 & 40 & 40 & 40 & $\ldots$ & $\ldots$ \\
\hline 080 & $38 / 34$ & $38 / 33$ & $35 / 33$ & $39 / 29$ & $30 / 25^{z}$ & $\ldots$ & 40 & 40 & 40 & 40 & $\ldots^{\mathrm{z}}$ & $\ldots$ \\
\hline
\end{tabular}

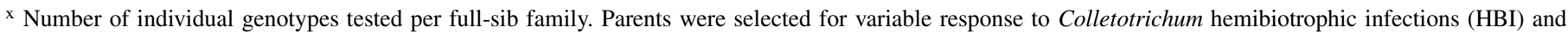
anthracnose crown rot (ACR) infection caused by Colletotrichum gloeosporioides and included two commercial cultivars and four selections from the North Carolina State University strawberry breeding program. TR = Treasure, CH = Chandler. $147=$ NCS 10-147, 185 = NCL 11-185, 304 = NCH 11-304, and 080 = NCS 10-080. Deviations from the original 40 individuals per family were due to plant death before sample collection 21 days after inoculation.

y Number of individuals included for the $C$. acutatum HBI experiment/number of individuals included for the $C$. gloeosporioides experiment.

${ }^{z}$ NCS $10-080 \times \mathrm{NCH} 11-304$ was only included in the HBI experiment due to insufficient plant numbers. 
with a hand sprayer (Solo model 419; https://www.Amazon.com/) just until runoff to ensure even inoculum density across all leaf surfaces. For ACR experiments, crowns were inoculated by applying $3 \mathrm{ml}$ of inoculum directly to the crown of each plant with a hand sprayer (Solo model 419). Both the HBI and ACR experiments were inoculated when plants were approximately 2 months old. To prevent cross-contamination from inoculum drift, plastic barriers were placed between main-plot treatments and greenhouse fans were turned off during inoculation. Barriers were removed and greenhouse fans were turned on once inoculation was complete. This method allowed plants to dry for 20 min to permit adherence of spores prior to initiation of overhead fine mist and to minimize runoff of inoculum. In addition, a $45-\mathrm{cm}$ gap was left between main-plot treatments to avoid crosscontamination of Colletotrichum spp. during incubation and regular plant maintenance. Inoculated plants were incubated for $48 \mathrm{~h}$ at $28 \pm 2{ }^{\circ} \mathrm{C}$ with periodic mist (3-s duration, 5-min interval) provided by 20 l/hVibroNet misters (Netafim USA, Fresno, CA). Mist was applied automatically by a greenhouse controller from 8: 00 A.M. to 8:00 P.M. to maintain humidity near $100 \%$. Overnight mist was not required to maintain leaf wetness because ambient relative humidity generally climbed above $90 \%$ by 10:00 P.M.. After misting was discontinued, the plants were set to day and night temperatures of 28 and $20^{\circ} \mathrm{C}$, respectively. Temperature and humidity data were collected by a Vantage Pro2 wireless weather station module (Davis Instruments Corp., Hayward, CA) located in the greenhouse.

Experiment design and disease assessment. The HBI experiment was laid out in a randomized complete block splitplot design with four replications. Each block was split and Colletotrichum spp. (C. gloeosporioides or C. acutatum) were randomly assigned. Ten individuals from each family and five clonal plants of each parental genotype were randomly assigned to each pathogen treatment within each replication. For the ACR experiment, a randomized complete block design with four replications was designed and 10 individuals from each family and five clonal plants of each parental genotype were randomly assigned to plots within each block. Samples were collected from the HBI experiment 21 days after inoculation by removing all inoculated leaves from individual plants and placing them in labeled plastic sandwich bags. Leaves were stored at $4{ }^{\circ} \mathrm{C}$ until analysis.

To evaluate severity of $\mathrm{HBI}$ of $C$. acutatum and C. gloeosporioides in strawberry leaf tissue, a modification of the paraquat protocol developed by Cerkauskas and Sinclair (1982) was used (R. L. Jacobs, unpublished data) (Rahman et al. 2013). PSLA scores were calculated from ImageJ (Abd-El-Haliem 2012) data in Microsoft Excel 2013 (Microsoft Corporation, Redmond, WA) and expressed as PSLA $(\%)=($ diseased leaf area/total leaf area $) \times 100$.

For ACR evaluations, individual plants were rated eight times for wilt severity at weekly intervals. Infection severity was assessed using a disease index of 0 to 5 , where $0=$ no wilt,
$1=$ youngest leaf wilted, $2=25 \%$ of leaves wilted, $3=50 \%$ of leaves wilted, $4=75 \%$ of leaves wilted, and $5=$ complete collapse. The area under the disease progress curve (AUDPC) was calculated for the ACR experiment as described previously (Shaner and Finney 1977). rAUDPC was calculated for each single-plant plot by dividing AUDPC scores by the maximum potential AUDPC for the experiment (Fry 1978). The maximum potential AUDPC is the AUDPC score that would be reached if disease were assessed at maximum (5.0) severity on every sample date. Selected infected crowns were examined by making a cross-section through the crown tissue to observe internal ACR symptoms. If symptoms were nontypical of ACR, diseased crown tissue was plated onto PDA for observation of colony and conidia morphology.

Data analysis. PSLA scores for each genotype infected by Colletotrichum spp. were examined using the means procedure (PROC MEANS) and univariate procedure (PROC UNIVARIATE) of the Statistical Analysis System (SAS) (version 9.4; SAS Institute, Cary, NC). Normality of the distribution and homogeneity of variance were evaluated with statistical moments and by plotting residual versus fitted values. To improve normality of the distribution and stabilize variance, a square root transformation was applied to PSLA data with the distribution anchored at 1.0. Homogeneity of variance was assessed through diagnostic plots of residual versus fitted values. Two-way analysis of variance (ANOVA) was performed on HBI data using the mixed-model procedure (PROC MIXED) of SAS (version 9.4; SAS Institute) and appropriate type III tests of fixed effects were also calculated.

Griffing's Method II, Model 1 was carried out to estimate the GCA effects of parents and SCA effects of crosses for C. gloeosporioides HBI, C. acutatum HBI, and ACR. Block and Colletotrichum treatment were considered fixed effects while GCA, SCA, and the error term were considered random effect. GCA estimates were back-transformed for presentation. In the case of resistance to $\mathrm{HBI}$, negative GCA values indicated that progeny of crosses including a particular parent had reduced PSLA measurements. Positive GCA values are associated with parents whose progeny had elevated PSLA measurements. SAS code developed by Isik (2009) for diallel mating designs was used to estimate combining abilities and partition variance components (VC). VC (\%) were calculated as the percentage of total variance contributed by a given parameter. The relative importance of additive and dominance effects on total genetic variance were assessed with the ratio of additive to dominance variance $\left(\sigma_{A}^{2} / \sigma_{D}^{2}\right)$ for each trait. The closer this ratio was to zero, the greater the additive component of genetic variance. The higher this ratio, the greater the proportion of dominance variance. Gain from selection was estimated based on full-sib family selection of the $(10 \%)$ most resistant progeny using the formula $G_{S}=k p c \sigma_{A}^{2} / \sqrt{\sigma_{P}^{2}}$, where $k=$ selection differential, $p=$ coefficient of parental control, and $c=$ coefficient of additive covariance of selected relatives as

TABLE 5. Analysis of variance of the general combining ability (GCA) and specific combining ability (SCA) of crosses screened for resistance to Colletotrichum hemibiotrophic foliar infection (HBI) of $C$. acutatum (Ca HBI) and C. gloeosporioides (Cg HBI) and anthracnose crown rot (ACR) caused by $C$. gloeosporioides $(C g \text { ACR })^{\mathrm{x}}$

\begin{tabular}{|c|c|c|c|c|c|c|c|}
\hline \multirow[b]{2}{*}{ Source of variation ${ }^{y}$} & \multirow[b]{2}{*}{$\mathrm{df}$} & \multicolumn{2}{|c|}{ Ca HBI } & \multicolumn{2}{|c|}{$C g$ HBI } & \multicolumn{2}{|c|}{$C g$ ACR } \\
\hline & & Estimate & $P>\mathrm{Z}$ & Estimate & $P>\mathrm{Z}$ & Estimate & $P>\mathrm{Z}$ \\
\hline GCA & 5 & 0.1812 & 0.0821 & 0.0670 & 0.1355 & 0.0265 & 0.0735 \\
\hline
\end{tabular}

x $P=$ probability.

y GCA refers to the average performance of a genotype across all hybrid combinations, while SCA is deviation of the performance of hybrid combinations from the expected based on parental GCA.

${ }^{z}$ Diallel analysis of $C$. gloeosporioides ACR based on 13 SCA degrees of freedom (df) due to insufficient plant numbers of that family. 
reported previously (Baltunis et al. 2007). Progress from selection was estimated from genetic gain using the formula $\mu_{\mathrm{F}}=\mu_{0}+$ (number of cycles $\times \mathrm{G}_{\mathrm{S}}$ ), where $\mu_{0}=$ the initial population mean and $\mu_{\mathrm{F}}=$ the final population mean. Correlation between traits was calculated using the correlate procedure (PROC CORR) in SAS and genetic correlation was calculated using the formula $r_{A}=$ $\sigma_{G i j}^{2} /\left(\sigma_{G i}^{2} \times \sigma_{G j}^{2}\right)^{1 / 2}$, where $\sigma_{G i j}^{2}=$ the genetic covariance between traits and $\sigma_{G i}^{2}$ and $\sigma_{G j}^{2}=$ the genetic VC of each trait.
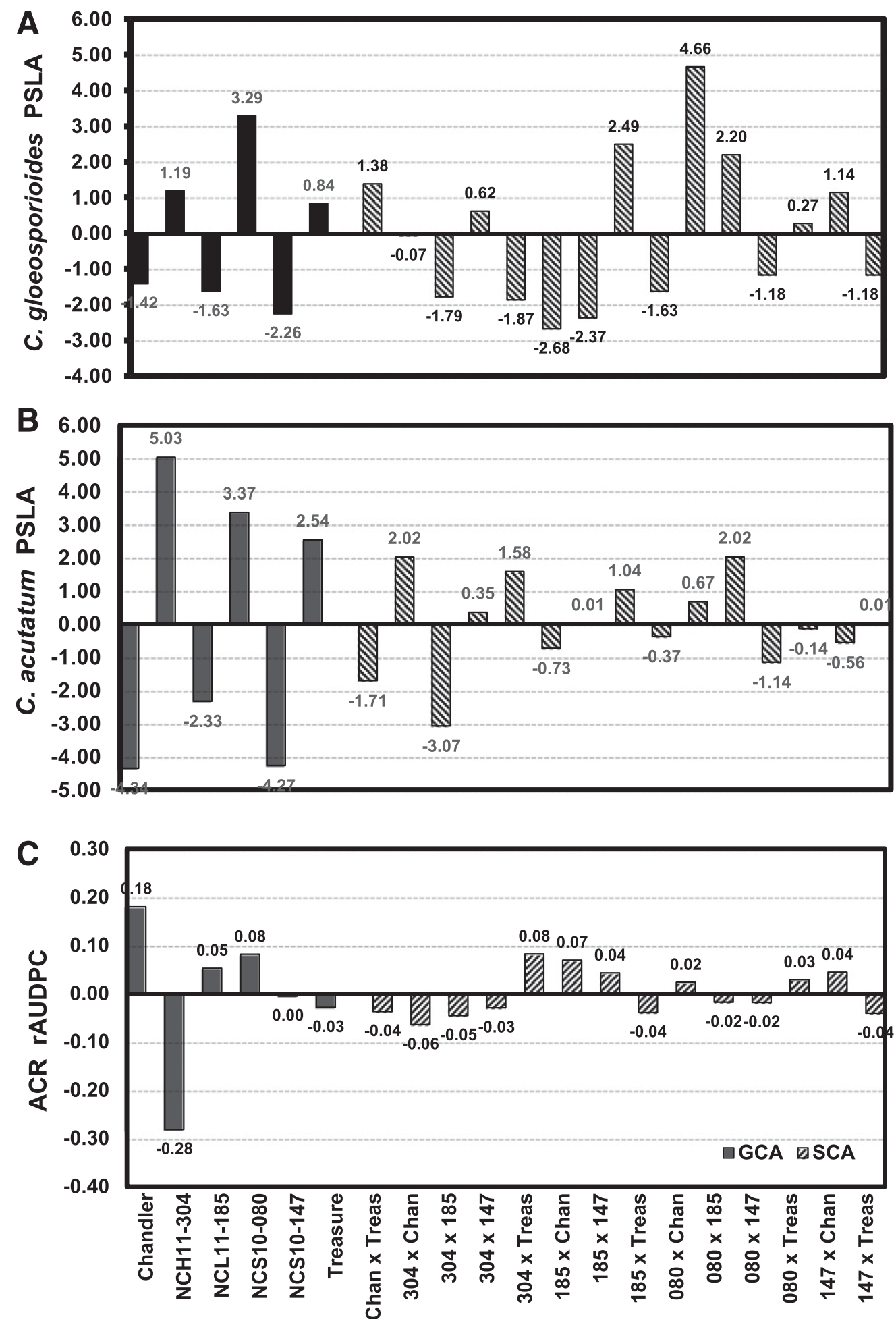

\section{Strawberry genotypes}

Fig. 1. General combining abilities (GCA) of parents and specific combining abilities (SCA) of crosses screened for resistance to A, Colletotrichum gloeosporioides and $\mathbf{B}$, C. acutatum hemibiotrophic infection. GCA refers to the average performance of a genotype across all hybrid combinations. SCA is deviation of the performance of hybrid combinations from the expected based on parental GCA. GCA and SCA response is measured in percent sporulating leaf area (PSLA). Negative values indicate that progeny of crosses including a particular parent had reduced PSLA measurements. Positive values are associated with parents whose progeny had elevated PSLA measurements. GCA of parents and SCA of crosses were screened for resistance to anthracnose crown rot (ACR) caused by $\mathbf{C}, C$. gloeosporioides. GCA and SCA response was measured as the relative area under the disease progress curve (rAUDPC), a proportion of observed to maximum potential disease over time. Negative GCA estimates are associated with parents whose progeny had overall reductions in ACR incidence while positive GCA estimates indicated parents whose progeny had higher incidence of ACR. 


\section{RESULTS}

In this study, ANOVA of HBI experimental factors revealed no significant differences for the fixed effects of block, Colletotrichum treatment, and the interaction of genotype-treatment. Significant effects of genotype $(P<0.0001)$, parent $(P=0.0141)$, and cross $(P=$ $0.0121)$ were detected and supported individual diallel analyses of HBI traits (Table 4). Diallel analysis revealed no significant effects of GCA and SCA for either HBI trait tested $(P<0.05)$; however, marginal $P$ values encouraged exploration of GCA and SCA effects (Table 5; Fig. 1). The lowest $P$ value for HBI traits $(P=0.0821)$ was associated with the GCA effect of $C$. acutatum HBI. GCA values were small for both $C$. acutatum and $C$. gloeosporioides HBI (less than $\pm 6.0 \%$ effect) but three genotypes had significant GCA effects for C. acutatum HBI (Table 6; Fig. 1). NCH 11-304 had a significant positive GCA effect of $5.03(P=0.0328)$. Chandler and NCS 10-147 had significant negative GCA effects of $-4.34(P=0.0431)$ and $-4.27(P=0.0489)$, respectively (Table 6). GCA estimates for C. gloeosporioides were smaller in effect and just one was found to be significant. NCS 10-080 had a significant positive GCA of 3.29 $(P=0.0490)$. No significant SCA effects were detected for any cross included in the HBI experiment (Table 6).

In the case of ACR, negative GCA estimates were associated with parents whose progeny had overall reductions in ACR incidence whereas positive GCA estimates indicated parents whose progeny had higher incidence of ACR (Table 6). Diallel analysis of ACR data found marginal but insignificant effects of GCA $(P=0.0735)$ and SCA $(P=0.0982)$ (Table 5). Chandler had a significant positive GCA of $0.18(P=0.012)$, indicating greater average susceptibility of hybrid combinations with Chandler. $\mathrm{NCH} 11-304$ had a significant negative GCA of $-0.28(P=0.0004)$, suggesting that hybrid combinations including $\mathrm{NCH} 11-304$ were, on average, more resistant to ACR (Fig. 1). No SCA effects were found for resistance to ACR (Table 6). Isolations confirmed that C. gloeosporioides was associated with crowns with ACR symptoms. Residual variance was high for the two HBI traits and contributed more than $92 \%$ of the total variance observed. Residual variance was lower for ACR, contributing $78 \%$ of the total variance (Table 7). Ratios of dominance variance to additive variance were similarly low for $C$. acutatum $\mathrm{HBI}(0.13)$ and $C$. gloeosporioides ACR (0.20) but were much higher for $C$. gloeosporioides HBI (0.91) (Table 7). Narrow-sense heritability estimates were 0.25 for C. acutatum HBI and 0.16 for $C$. gloeosporioides HBI; however, it was higher for C. gloeosporioides ACR (0.61). Estimates of genetic gain for HBI traits were highly positively correlated for the two pathogens $\left(\mathrm{r}_{\mathrm{A}}=0.98\right)$ but negative correlations were found between C. acutatum $\mathrm{HBI}$ and $\mathrm{ACR}\left(\mathrm{r}_{\mathrm{A}}=-0.85\right)$ as well as between C. gloeosporioides $\mathrm{HBI}$ and ACR $\left(\mathrm{r}_{\mathrm{A}}=-0.61\right)$ (Table 8).

\section{DISCUSSION}

ACR and AFR are two of the most devastating diseases in strawberry production and have been a significant financial concern to strawberry growers in North Carolina and the southeastern United States (Giménez and Ballington 2002; Howard et al. 1992; Poling 2008). Although fungicides are available to manage these diseases, host resistance would be a more cost-effective and economical option to strawberry growers. In this study, six strawberry genotypes were selected to develop 15 full-sib families through a half-diallel mating design to characterize the inheritance of rate-limiting resistance to $C$. acutatum and $C$. gloeosporioides and to estimate genetic parameters governing inheritance of resistance to ACR incited by $C$. gloeosporioides. Considering the strawberry genotypes, populations, and parameters of inheritance of resistance tested in this investigation, resistance to Colletotrichum HBI in strawberry leaf tissue appeared to be a novel and valuable trait which may provide rate-limiting resistance in strawberry nurseries and fruiting fields. These data forward the hypothesis that HBI and ACR resistance traits in strawberry breeding programs could provide greater durability for anthracnose resistance.

Analysis of combining abilities for the HBI traits found significant (positive and negative) GCA effects for some parental genotypes assessed in this study. NCS 10-147 was ranked in previous work as the most resistant of 18 genotypes screened for resistance to $C$. acutatum $\mathrm{HBI}$ (Table 1). In line with this result, the current study found that NCS 10-147 had a GCA of -4.27 and conveyed resistance to its progeny. Though NCS 10-147 was identified as resistant in the previous study, both of its parents (Chandler and Treasure) were observed to be susceptible to Colletotrichum HBI. The relative susceptibility of Chandler and Treasure were confirmed by high PSLA scores in the current study, averaging 38.32 and $48.73 \%$, respectively. The family mean of Chandler $\times$ Treasure was $25.04 \%$ for $C$. acutatum $\mathrm{HBI}$, much lower than the midparent value of 43.53\%. Resistance of NCS 10-147 and hybrids of Chandler $\times$ Treasure supports the significant negative GCA of Chandler and its capacity to produce resistant progeny, despite its own susceptibility.

Environmental parameters, differences in plant physiology, inoculation efficiency, and detached-leaf assays represented sources of experimental error which could affect the accuracy of evaluating host resistance phenotypes. Smith and Black (1987) found that strong genotype-environment interactions affected the expression of resistance to these pathogens, noting that apparent field resistance may not be representative of true genetic resistance. In this study, we employed image-based analysis to improve the accuracy and precision of PSLA measurements of HBI resistance. Despite high (92.4 and 92.2\%) residual variance estimates reflecting the inherent variability of hemibiotrophic foliar infections, observable genetic variance was estimated for both HBI traits. C. acutatum HBI had a GCA variance of 0.1812 (6.7\%) and SCA variance of $0.0246(0.9 \%)$. A low dominance/additive variance ratio $(0.13)$ for this trait suggests additive genetic control for resistance to $C$. acutatum HBI. C. gloeosporioides $\mathrm{HBI}$ had a GCA variance of $0.0670(4.1 \%)$ and SCA of 0.0607 (3.7\%). This resulted in a much higher dominance/additive variance ratio

TABLE 6. Parental means and general combining abilities for resistance to hemibiotrophic foliar infections (HBI) of Colletotrichum acutatum (Ca HBI) and $C$. gloeosporioides $(\mathrm{Cg} \mathrm{HBI})$ and anthracnose crown rot $(\mathrm{ACR})$ caused by $C$. gloeosporioides $(\mathrm{Cg} \mathrm{ACR})$ of six strawberry genotypes used as parents in a half-diallel $\operatorname{cross}^{\mathrm{z}}$

\begin{tabular}{|c|c|c|c|c|c|c|}
\hline \multirow[b]{2}{*}{ Parent } & \multicolumn{2}{|c|}{ Сa HBI } & \multicolumn{2}{|c|}{$C g$ HBI } & \multicolumn{2}{|c|}{$C g$ ACR } \\
\hline & Mean PSLA & GCA & Mean PSLA & GCA & Mean rAUDPC & GCA \\
\hline Chandler & 38.32 & $-4.34 * \mathrm{z}$ & 34.36 & -1.42 & 0.42 & $0.18^{*}$ \\
\hline $\mathrm{NCH} 11-304$ & 38.71 & $5.03 *$ & 41.21 & 1.19 & 0.04 & -0.28 *** \\
\hline NCS $10-080$ & 29.83 & 3.37 & 29.82 & $3.29 *$ & 0.38 & 0.08 \\
\hline NCS $10-147$ & 28.64 & $-4.27 *$ & 30.19 & -2.25 & 0.16 & -0.01 \\
\hline Treasure & 48.73 & 2.54 & 50.95 & 0.84 & 0.19 & -0.03 \\
\hline
\end{tabular}

${ }^{\mathrm{z}}$ PSLA $=$ percent sporulating leaf area, back-transformed for presentation; GCA = general combining ability; and rAUDPC $=$ relative area under the disease progress curve. Negative GCA value means it contributes to a lower HBI score. Level of significance: *, **, and *** indicate $P<0.05,0.01$, and 0.001 , respectively. 
(0.91) than estimated for $C$. acutatum HBI, suggesting that this trait was under nearly equal dominance and additive genetic control

Combining ability analysis found significant GCA effects for two of the parental genotypes tested. Chandler had a significant positive GCA $(0.18)$, indicating that its hybrid combinations averaged an $18 \%$ increase in rAUDPC score and greater susceptibility to ACR. NCH 11-304 had a significant negative GCA $(-0.28)$ and conveyed a $28 \%$ average decrease in rAUDPC to its progeny. $\mathrm{NCH} 11-304$ is the progeny of a cross of Winter Dawn $\times$ NCH 09-068, a genotype found to be one of the most resistant of 18 genotypes evaluated for resistance to ACR (Table 1). Additionally, Osorio et al. (2014) included NCH 09068 as a parent in their study of inheritance of resistance to ACR. Their study found that NCH 09-068 ranked just behind cultivar Pelican in terms of resistance conferred and was one of the best parents conveying resistance to ACR.

SCA variance $(0.0053)$ contributed $3.6 \%$ of the total variance, similar to the $3.7 \%$ SCA variance found for $C$. gloeosporioides HBI. GCA variance was 0.0265 and represented a much larger VC percentage (17.9\%) than other genetic VC observed in this study. Similar to $C$. acutatum HBI, the ACR trait produced a low dominance/additive variance ratio (0.20), indicating a primarily additive genetic control of resistance to ACR in this population. These findings agree with some inheritance studies of this trait and disagree with others. For example, Osorio et al. (2014) found that dominance variance was roughly one-third of the additive variance for the population screened in North Carolina. This was similar to the current study's finding of dominance variance representing roughly one-fifth the additive variance. On the other hand, Anciro et al. (2018) described resistance at FaRCgl to be dominant in nature.

Genetic improvement of quantitative traits requires reliable estimates of heritability to structure an effective breeding program. Moderately low narrow-sense heritabilities of 0.25 and 0.16 were found for C. acutatum and C. gloeosporioides HBI, respectively. Heritabilities in this range are not uncommon for quantitative disease resistance traits or for traits linked to the fitness of individuals. This association was confirmed in a previous study, which found that low heritabilities were caused by consistently high residual variance rather than low additive variance (Merilä and Sheldon 2000). It is unclear whether the low percentage of total VC

TABLE 7. Variance components (VC) and heritabilities for resistance to hemibiotrophic foliar infections (HBI) of Colletotrichum acutatum ( $\mathrm{Ca} \mathrm{HBI}$ ) and $C$. gloeosporioides $(\mathrm{Cg} \mathrm{HBI})$ and anthracnose crown rot (ACR) caused by C. gloeosporioides $(\mathrm{Cg} \mathrm{ACR})^{\mathrm{y}}$

\begin{tabular}{|c|c|c|c|c|c|c|}
\hline \multirow[b]{2}{*}{$\mathrm{VC}^{\mathrm{z}}$} & \multicolumn{2}{|c|}{ Ca HBI } & \multicolumn{2}{|c|}{$C g \mathrm{HBI}$} & \multicolumn{2}{|c|}{$C g$ ACR } \\
\hline & Estimate & $\mathrm{VC}(\%)$ & Estimate & $\mathrm{VC}(\%)$ & Estimate & $\mathrm{VC}(\%)$ \\
\hline$\sigma_{G C A}^{2}$ & 0.1812 & 6.7 & 0.0670 & 4.1 & 0.0265 & 17.9 \\
\hline$\sigma_{S C A}^{2}$ & 0.0246 & 0.9 & 0.0607 & 3.7 & 0.0053 & 3.6 \\
\hline$\sigma_{P}^{2}$ & 2.9046 & $\ldots$ & 1.6941 & $\ldots$ & 0.1747 & $\ldots$ \\
\hline$\sigma_{\Delta}^{2}$ & 0.7248 & $\ldots$ & 0.2680 & $\ldots$ & 0.1062 & $\ldots$ \\
\hline$\sigma_{D}^{A_{1}^{2}}$ & 0.0984 & $\ldots$ & 0.2428 & $\ldots$ & 0.0214 & $\ldots$ \\
\hline$\sigma_{e}^{2}$ & 2.5176 & 92.4 & 1.4994 & 92.2 & 0.1164 & 78.5 \\
\hline$h^{2}$ & 0.25 & $\ldots$ & 0.16 & $\ldots$ & 0.61 & $\ldots$ \\
\hline$H^{2}$ & 0.28 & $\ldots$ & 0.30 & $\ldots$ & 0.73 & $\ldots$ \\
\hline$\sigma_{D}^{2} / \sigma_{A}^{2}$ & 0.13 & $\ldots$ & 0.91 & $\ldots$ & 0.20 & $\ldots$ \\
\hline$G_{S}$ & 0.37 & $\ldots$ & 0.18 & $\ldots$ & 0.22 & $\ldots$ \\
\hline
\end{tabular}

y $\mathrm{VC}(\%)$ refer to the percentage of total observed variance accounted for by each VC.

${ }^{\mathrm{z}}$ Estimates of VC: $\sigma_{G C A}^{2}=$ general combining ability variance, $\sigma_{S C A}^{2}=$ specific combining ability variance, $\sigma_{P}^{2}=$ phenotypic variance, $\sigma_{A}^{2}=$ additive genetic variance, $\sigma_{D}^{2}=$ dominance genetic variance, $\sigma_{e}^{2}=$ residual error, $h^{2}=$ narrow-sense heritability, $H^{2}=$ broad-sense heritability, $\sigma_{D}^{2} / \sigma_{A}^{2}=$ ratio of dominance/additive variance, and $G_{S}=$ gain $(10 \%)$ based on full-sib family selection. accurately described the genetic control of HBI traits or if genetic variance was obscured by higher environmental variance. A moderate narrow-sense heritability estimate (0.61) for ACR suggested that this trait should respond well to selection of resistant genotypes. Other ACR resistance studies have reported narrowsense heritability estimates of 0.16 (Osorio et al. 2014), 0.30 , and 0.47 (Anciro et al. 2018).

Estimates of gain from selection were used to estimate selection progress for each trait. The greatest relative gains from selection would be seen for C. gloeosporioides ACR. High levels of resistance (similar to the level seen in Pelican) could be achieved in two cycles of selection. Progress would be much slower for the HBI traits. Approximately three cycles would be required for each $10 \%$ decrease in PSLA for C. acutatum HBI but a similar decrease for $C$. gloeosporioides HBI would require six or more cycles. Therefore, gain from selection was predicted to be high for ACR resistance, moderate for $C$. acutatum $\mathrm{HBI}$ resistance, and low for C. gloeosporioides $\mathrm{HBI}$ resistance.

A strong genetic correlation $\left(\mathrm{r}_{\mathrm{A}}=0.98\right)$ was found between resistance to $C$. acutatum $\mathrm{HBI}$ and $C$. gloeosporioides $\mathrm{HBI}$, suggesting that resistance to these two Colletotrichum spp. may be controlled by common genes in strawberry leaf tissue in the tested population. It would be desirable to simultaneously improve populations that confer resistance to multiple species of Colletotrichum. Selecting for increased resistance to HBI for one Colletotrichum sp. should produce gains in resistance to the other. On the other hand, negative genetic correlations between ACR and both HBI traits suggest that resistance in crown tissue is inherited independently of resistance in leaf tissue in the population evaluated. Genetic correlation was highly negative across tissue types and between species, with $\mathrm{r}_{\mathrm{A}}=-0.85$ for $C$. acutatum $\mathrm{HBI}$ and $C$. gloeosporioides ACR. Genetic correlation was moderately negative between tissue types for $C$. gloeosporioides, with $\mathrm{r}_{\mathrm{A}}=$ -0.61 for $C$. gloeosporioides HBI and ACR. The strong negative correlations between resistance to $\mathrm{HBI}$ and ACR may be a consequence of the number of parents as well as parental resistance phenotypes selected for this study. Six parents were chosen to represent a range of resistance responses to both HBI and ACR. Of these, NCL 11-185 and Treasure have opposing resistance phenotypes to HBI and ACR and may have contributed to this negative correlation. The negative genetic correlations in this study indicate that simultaneously selecting for gains in resistance to HBI and ACR would be slow in the present population; however, there is no direct evidence to suggest that simultaneous selection for resistance to HBI and ACR would not be possible in a broader pool of randomly mated individuals. A lack of correlation of HBI and AFR resistance caused by $C$. acutatum has also been documented (Rahman et al. 2013).

In conclusion, our study is the first to report on the inheritance of hemibiotrophic resistance in strawberry, a potentially powerful tool in the suppression of Colletotrichum epidemics. We found a high genetic correlation of resistance to HBI of C. acutatum and C. gloeosporioides, suggesting that independent evaluations may not be necessary and that these resistance traits may be advanced

TABLE 8. Genetic correlations between resistance to Colletotrichum acutatum hemibiotrophic foliar infection $(C a \mathrm{HBI}), C$. gloeosporioides $(C g \mathrm{HBI})$, and C. gloeosporioides anthracnose crown $\operatorname{rot}(C g \mathrm{ACR})$ in a strawberry population tested by half-sib analysis ${ }^{z}$

\begin{tabular}{lccc}
\hline Trait & $C a$ HBI & $C g$ HBI & $C g$ ACR \\
\hline$C a$ HBI & $\ldots$ & 0.98 & -0.85 \\
$C g$ HBI & $\ldots$ & $\ldots$ & -0.61 \\
$C g$ ACR & $\ldots$ & $\ldots$ & $\ldots$ \\
\hline
\end{tabular}

z Genetic correlation was calculated as $\mathrm{r}_{\mathrm{A}}=\sigma_{G i j}^{2} /\left(\sigma_{G i}^{2} \times \sigma_{G j}^{2}\right)^{1 / 2}$, where $\sigma_{G i j}^{2}=$ the genetic covariance between traits and $\sigma_{G i}^{2}$ and $\sigma_{G j}^{2}=$ the genetic variance components of each trait. 
simultaneously. Selecting for rate-limiting resistance to HBI of one Colletotrichum spp. should also convey resistance to the other. We also found a strong negative correlation of resistance to HBI and ACR of $C$. gloeosporioides, indicating that resistance to this pathogen may be inherited independently in the current population. This study also identified useful sources of resistance to HBI and ACR that may be used in breeding programs and future inheritance studies. Environmental replication incorporated into future studies will permit estimates of environmental variance as a component of nonadditive genetic variance. Current research is focused on developing and screening a mapping population from two of the strawberry lines identified in this study. We are conducting genomewide association mapping to detect DNA markers linked to resistance to Colletotrichum spp. Enhanced breeding methodologies that control the large residual variance associated with resistance to HBI in newly discovered genetic resources should improve estimates of the rate of genetic gain and will ultimately provide more durable resistance against these two hemibiotrophic pathogens of strawberry.

\section{ACKNOWLEDGMENTS}

We thank J. Osborne for help with statistical analysis and the Plants for Human Health Institute, Kannapolis, NC for providing greenhouse and laboratory facilities.

\section{LITERATURE CITED}

Abd-El-Haliem, A. 2012. An unbiased method for the quantitation of disease phenotypes using a custom-built macro plugin for the program ImageJ. Methods Mol. Biol. 835:635-644.

Anciro, A., Mangandi, J., Verma, S., Peres, N., Whitaker, V. M., and Lee, S. 2018. FaRCg 1: A quantitative trait locus conferring resistance to Colletotrichum crown rot caused by Colletotrichum gloeosporioides in octoploid strawberry. Theor. Appl. Genet. 131:2167-2177.

Ballington, J. R., Shuman, J. L., Hokanson, S. C., Smith, B. J., and Giménez, G. 2002. Breeding strawberries (Fragaria $\times$ ananassa) for resistance to anthracnose caused by Colletotrichum acutatum. Acta Hortic. 567:89-92.

Baltunis, B. S., Huber, D., White, T. L., Goldfarb, B., and Stelzer, H. E. 2007. Genetic gain from selection for rooting ability and early growth in vegetatively propagated clones of loblolly pine. Tree Genet. Genomes 3:227-238.

Baroncelli, R., Zapparata, A., Sarrocco, S., Sukno, S. A., Lane, C. R., Thon, M. R., Vannacc, G., Holub, E., and Sreenivasaprasad, S. 2015. Molecular diversity of anthracnose pathogen populations associated with UK strawberry production suggests multiple introductions of three different Colletotrichum species. PLoS One 10:e0129140.

Cerkauskas, R. F., and Sinclair, J. B. 1982. Effect of paraquat on soybean pathogens and tissues. Trans. Br. Mycol. Soc. 78:495-502.

Damm, U., Cannon, P. F., Woudenberg, J. H. C., and Crous, P. W. 2012. The Colletotrichum acutatum species complex. Stud. Mycol. 73:37-113.

Delp, B. R., and Milholland, R. D. 1980. Factors affecting disease development of strawberries infected with Colletotrichum fragariae. Phytopathology 70:566-567.

Denoyes-Rothan, B., Guérin, G., Délye, C., Smith, B., Minz, D., Maymon, M., and Freeman, S. 2003. Genetic diversity and pathogenic variability among isolates of Colletotrichum species from strawberry. Phytopathology 93:219-228.

Denoyes-Rothan, B., Guérin, G., Lerceteau-Köhler, E., and Risser, G. 2005. Inheritance of resistance to Colletotrichum acutatum in Fragaria $\times$ ananassa. Phytopathology 95:405-412.

Freeman, S., and Katan, T. 1997. Identification of Colletotrichum species responsible for anthracnose and root necrosis of strawberry in Israel. Phytopathology 87:516-521.

Fry, W. E. 1978. Quantification of general resistance of potato cultivars and fungicide effects for integrated control of potato late blight. Phytopathology $68: 1650-1655$
Gan, P., Ikeda, K., Irieda, H., Narusaka, M., O’Connell, R. J., Narusaka, Y., Takano, Y., Kubo, Y., and Shirasu, K. 2013. Comparative genomic and transcriptomic analyses reveal the hemibiotrophic stage shift of Colletotrichum fungi. New Phytol. 197:1236-1249.

Giménez, G., and Ballington, J. R. 2002. Inheritance of resistance to Colletotrichum acutatum Simmonds on runners of garden strawberry and its backcrosses. HortScience 37:686-690.

Griffing, B. 1956. Concept of general and specific combining ability in relation to diallel crossing systems. Aust. J. Biol. Sci. 9:463-493.

Gupton, C. L., and Smith, B. J. 1991. Inheritance of resistance to Colletotrichum species in strawberry. J. Am. Soc. Hortic. Sci. 116:724-727.

Howard, C. M., Mass, J. L., Chandler, C. K., and Albregts, E. E. 1992. Anthracnose of strawberry caused by the Colletotrichum complex in Florida. Plant Dis. 76:976-981.

Isik, F. 2009. Analysis of diallel mating designs. North Carolina State University, Raleigh, NC.

Leandro, L. F. S., Gleason, M. L., Nutter, F. W., Jr., Wegulo, S. N., and Dixon, P. M. 2001. Germination and sporulation of Colletotrichum acutatum on symptomless strawberry leaves. Phytopathology 91:659-664.

Leandro, L. F. S., Gleason, M. L., Nutter, F. W., Jr., Wegulo, S. N., and Dixon, P. M. 2003. Influence of temperature and wetness duration on conidia and appressoria of Colletotrichum acutatum on symptomless strawberry leaves. Phytopathology 93:513-520.

Legard, D. E. 2000. Colletotrichum diseases of strawberry in Florida. Pages 292-299 in: Colletotrichum: Host Specificity, Pathology, and HostPathogen Interaction. D. Prusky, S. Freeman, and M. B. Dickman, eds. The American Phytopathological Society, St. Paul, MN.

MacKenzie, S. J., Legard, D. E., Timmer, L. W., Chandler, C. K., and Peres, N. A. 2006. Resistance of strawberry cultivars to crown rot caused by Colletotrichum gloeosporioides isolates from Florida is nonspecific. Plant Dis. 90:1091-1097.

MacKenzie, S. J., Mertely, J. C., and Peres, N. A. 2009. Curative and protectant activity of fungicides for control of crown rot of strawberry caused by Colletotrichum gloeosporioides. Plant Dis. 93:815-820.

Merilä, J., and Sheldon, B. C. 2000. Lifetime reproductive success and heritability in nature. Am. Nat. 155:301-310.

Osorio, L. F., Pattison, J. A., Peres, N. A., and Whitaker, V. M. 2014. Genetic variation and gains in resistance of strawberry to Colletotrichum gloeosporioides. Phytopathology 104:67-74.

Parlevliet, J. E. 1979. Components of resistance that reduce the rate of epidemic development. Annu. Rev. Phytopathol. 17:203-222.

Poling, E. B. 2008. Anthracnose on strawberry: Its etiology, epidemiology, and pathology, together with management strategies for strawberry nurseries: Introduction to the workshop. HortScience 43:59-65.

Rahman, M., Louws, F. J., and Ballington, J. 2013. Role of foliar hemibiotrophic and fruit resistance in anthracnose-resistant strawberry genotypes for annual hill plasticulture systems. Ann. Appl. Biol. 163:102-113.

Rahman, M., Ojiambo, P., and Louws, F. J. 2015. Initial inoculum and spatial dispersal of Colletotrichum gloeosporioides, the causal agent of strawberry anthracnose crown rot. Plant Dis. 99:80-86.

Ram, M. 2014. Plant Breeding Methods. PHI Learning Pvt. Ltd., Delhi, India.

Shaner, G., and Finney, R. E. 1977. Effect of nitrogen-fertilization on expression of slow-mildewing resistance in Knox wheat. Phytopathology 67: 1051-1056.

Smith, B. J. 2008. Epidemiology and pathology of strawberry anthracnose: A North American perspective. HortScience 43:69-73.

Smith, B. J., and Black, L. L. 1987. Resistance of strawberry plants to Colletotrichum fragariae affected by environmental conditions. Plant Dis. 71: 834-837.

Smith, B. J., and Spiers, J. M. 1982. Evaluating techniques for screening strawberry seedlings for resistance to Colletotrichum fragariae. Plant Dis. 66:559-561.

Sutton, B. C. 1992. The genus Glomerella and its anamorph Colletotrichum. Pages 1-26 in: Colletotrichum: Biology, Pathogenicity, and Control. J. A. Bailey and M. J. Jeger, eds. CAB International, Wallingford, UK.

Van der Plank, J. E. 1968. Disease Resistance in Plants. Academic Press, New York.

Weir, B. S., Johnston, P. R., and Damm, U. 2012. The Colletotrichum gloeosporioides species complex. Stud. Mycol. 73:115-180. 